\title{
A Study of the Difficulties and Instructional Support Related to Spoken Interaction in an EMI Course for Higher Education Students
}

\author{
Mei-Ying Chien, $\mathrm{PhD}$ \\ National Dong Hwa University, Taiwan \\ Martin Valcke, $\mathrm{PhD}$ \\ Ghent University, Ghent, Belgium \\ (iD) https://orcid.org/0000-0001-9544-4197
}

Contact: creju@unilag.edu.ng

\section{Abstract}

The use of English as a medium of instruction (EMI) in higher education is considered a vehicle in nonEnglish-speaking countries for the purpose of internationalization, enhancing students' employability, and international competition. Many higher education institutions in Europe adapted their curriculum and started teaching in English, while enrolling international students from Erasmus programs and non-European countries. This study builds on an EMI course set within a Belgian university. Six students whose second language was English were interviewed to identify and explore their motivation, difficulties, and instructional support as it relates to their spoken interaction during the class. The findings revealed that (a) students' motivation and willingness to communicate during English-as-a-second-language spoken interaction was related to their English language self-efficacy, the study topic, and the learning environment; (b) students' spoken interaction seemed restricted due to difficulties including academic language use, understanding the academic content, and their attitudes toward the learning activity; and (c) instructional support, namely, social-emotional, cognitive, and language support, was perceived by students to boost their willingness to communicate and confidence to be involved in spoken interaction.

Keywords: EMI; spoken interaction; L2 students; instructional support; higher education

Date Submitted: August 8, 2019 | Date Published: May 28, 2020

\section{Recommended Citation}

Chien, M.-Y., \& Valcke, M. (2020). A study of the difficulties and instructional support related to spoken interaction in an EMI course for higher education students. Journal of Educational Research and Practice, 10, 129-144. https://doi.org/10.5590/JERAP.2020.10.1.09

\section{Introduction}

The internationalization of higher education has affected both policy making and educational practice. The use of English as a medium of instruction (EMI) for tertiary education has been widely adopted and implemented by non-English speaking countries in Europe and Asia for different driving reasons. For example, at governmental level, it is viewed as a strategy to enhance national competitiveness in innovation

This study was funded by grant (MOST 107-2918-I-259-001) from the Ministry of Science and Technology, Taiwan. We also like to thank for the students participating in this study. 
and knowledge production ( $\mathrm{Hu}, 2007)$. At an institutional level, it is adopted as a means for facilitating internationalization of higher education (Piller \& Cho, 2013), enhancing employability of their graduates in the domestic and global markets (Pecorari et al., 2011), and raising the prestige/ranking of universities (Wilkinson, 2013).

Previous literature reflects benefits and challenges of these global EMI phenomena and related policies in higher education. However, less attention is paid to the nature of instructional support given to students when embracing EMI or other instructional languages.

EMI research points at the critical nature of students' language proficiency as the key factor limiting their interactions and learning in class. This limitation affects the study of disciplinary content. Due to inadequate English proficiency, English-as-a-second-language (L2) students have difficulties understanding the lecturers, participating in classroom interaction, using English to communicate about disciplinary content, leading to the need of more time for course completion (Airey, 2011; Hellekjær, 2010;Tsuneyoshi, 2005; Webb, 2002). Looking at key L2 language difficulties experienced by students and lecturers, Tatzl (2011) concluded that "spoken interaction," followed by "writing," is considered the most demanding language skill. Following the above, "spoken interaction" is defined by this study as students actively participating in classroom interaction and using English to communicate disciplinary content (Ferris \& Tagg, 1996; Hellsten \& Prescott, 2004; Rousell et al., 2017).

Theoretical explanations have been put forward to explain the weaker learning performance resulting from being involved in EMI-settings; see, for example, a focus on cognitive load theory (Rousell et al., 2017). The present study does not focus on learning performance, but rather on factors influencing the challenge to speak in EMI settings. This leads to an exploration of the following factors: self-efficacy, motivation, willingness to communicate (WTC), and instructional support. The theoretical and empirical exploration of these factors leads to the implementation of this qualitative case study.

\section{Self-Efficacy and Motivation}

Self-efficacy is defined as "beliefs in one's capabilities to organize and execute courses of action required to produce given attainments" (Bandura, 1997, p. 3). Self-efficacy is crucial when students self-evaluate learning tasks and set their academic goals (Kim et al., 2015); high self-efficacy leads to a strong sense of competence, which can help cognitive process and academic performance (Vasile et al., 2011). Linking this to the EMI field, self-efficacy is also seen as a predictor of language learning outcomes (Kim, et al., 2015). Developing students' self-efficacy is, according to Gist and Mitchell (1992), especially linked to the extent to which students experience positive feedback about their actions. There is hardly sufficient research available in the EMIresearch context, though Pajares and Johnson (1996) stressed that students' writing improves in relation to substantial positive feedback on their performance.

Motivation in L2 is defined as "referring to the extent to which the individual works or strives to learn the language because of a desire to do so and the satisfaction experienced in this activity" (Gardner, 1985, p. 10). Motivation is closely related to self-efficacy; students who have high self-efficacy tend to have high motivation for tasks and for producing better results (Rahman et al., 2010). Dörnyei (2003, p. 23) highlighted the need of focusing on instructor's role in language classroom, and provided a framework of a motivational teaching practice consisting of four main dimensions: (a) creating the basic motivational conditions, (b) generating initial student motivation, (c) maintaining and protecting motivation, and (d) encouraging positive retrospective self-evaluation. 
Building on self-determination theory (Ryan \& Deci, 2000), teachers can boost students' motivation by addressing their basic psychological needs. Their need for autonomy could be boosted by giving students options, choice and a hand in task definition (see, e.g., Haerens et al., 2015). The need for belonging could be enhanced by fostering sharing, collaboration and developing a fruitful teacher-student interaction (Chen et al., 2015). The need for competence can be boosted by giving students sufficient feedback, opportunities to exercise and acting out (Vansteenkiste et al., 2004). Nevertheless, hardly sufficient literature is available as to studying this in an EMI setting.

Previous studies show that self-efficacy and motivation-in interaction-influence academic performance (Jackson, 2002; Komarraju \& Nadler, 2013; Shih \& Alexander, 2000; Zimmerman \& Kitsantas, 2005). High self-efficacy will increase motivation and motivation achievement (Woolfork, 2008). Ersanli's (2015) findings verified the connection between students' self-efficacy beliefs and language learning motivation. Wong (2005) found that students who have high writing self-efficacy beliefs are more motivated in earning a good grade and participating in L2 writing tasks. Rahman et al. (2010) found strong relationships between self-efficacy in English (L2) and achievement motivation in the subject taught in English. C. Wang et al. (2013) argued that it is crucial to enhance English language learners' self-efficacy beliefs in classroom teaching approaches.

\section{Willingness to Communicate (WTC)}

McCroskey and Baer (1985) introduced the construct of WTC to explain individual differences in firstlanguage (L1) communication. It is conceptualized as the probability to engage in communication when given the choice. The WTC construct has also been used to investigate and analyze L2 learners' engagement in communication (Kang 2005; Leger \& Storch, 2009; Mehrgan, 2013; Zarrinabadi, 2014); WTC in L2 is defined as "language learners' tendency to initiate discourse in a particular context with some individuals" (Mehrgan, 2013, p. 172). WTC in L2 is found to display dual characteristics: the trait-like WTC and the situational WTC (Dörnyei, 2005); the trait-like view of WTC refers to personality-based predisposition such as self-perceived communication competence, whereas the situational view of WTC refers to the contextual-based predisposition such as the type of interlocutors (peers and/or lecturers;McCroskey \& Baer, 1985; McCroskey \& Richmond, 1991; Maclintyre et al., 1998).

Kang (2005, p. 278) defined the importance of WTC for L2 learners as follows: (a) L2 learners with a high WTC are more likely to use L2 in authentic communication; (b) students can function as autonomous learners, making independent efforts to learn the language through communication; and (c) students can extend their learning opportunities, becoming involved in learning activities both inside and outside classrooms. Linking WTC to EMI contexts and spoken interaction in particular, Mehrgan (2013) stated that interaction, particularly students' WTC in L2, plays an essential role in the development of language. "Spoken interaction" is as such key for L2 students, not only as a means of communicating disciplinary content but also an avenue to raise students' self-efficacy in English.

Zarrinabadi (2014) identified the factors affecting L2 WTC, such as choice of a topic, student's perceptions, type of task, type of interlocutors, interlocutors' interactions, and interaction patterns; these variables reflect both trait-like and situational views of WTC and have been found complementing each other. For example, Kang (2005) found that learners' sense of security, excitement, and responsibility changes according to the topic, interlocutors, or the learning context. Leger and Storch (2009) found that learners' self-confidence increases over time and as such their WTC in L2 in the classroom; their findings also highlighted the complex and dynamic nature of the interplay between self-confidence, anxiety and perception of the learning environment. 


\section{Instructional Support for L2 Students}

In an EMI context, it can be assumed that more interactions lead to better learning and language development. Hence, how to raise students' self-efficacy, motivation and situational WTC in view of increased and improved spoken interaction in EMI settings? Such concern brings to the provision of instructional support for L2 students.

Based on the relationship between self-efficacy, self-regulated learning and academic achievement in language learning, Kim et al. (2015) encouraged teachers to give appropriate feedback about student performance to boost their self-efficacy. Also, Mohd Khatib and Maarof (2015) stated the importance of raising L2 students' self-efficacy; they stressed as support mechanisms, such as to give positive feedback and encouragement in oral communication, provide room for discussion, allow working in groups, and allow observing role models (peers/lecturers) that model task performance.

Kang's (2005) findings revealed that situational WTC in L2 emerged from the interaction between excitement, responsibility, and security. These are influenced by the aspects of the conversation settings, such as interlocutor, topic, and conversational context. Based on such findings, he tried invoking situational WTC by paying attention to the topic given to L2 learners and how this should be aligned with their interest, knowledge and experience about the topic. Also, he stressed to set up a safe environment to lessen learners' fear/anxiety about making mistakes. Zarrinabadi's (2014) findings reiterated the importance of teacher's decisions about the choice of a topic, teacher's waiting time and support experienced during speaking through short confirmatory phrases or smiling. He added very specific suggestions, such as a negotiation of the speech topics, giving students' choices, focusing on student knowledge, being aware of the impact of error correction, allotting sufficient time prior to expecting answers to questions, and creating a supportive learning environment through verbal and non-verbal communication strategies on the part of the teacher.

\section{Research Questions}

This study was conducted to explore L2 students' self-reported perceptions of actual spoken interaction and the difficulties as experienced by them in an academic context. Building on the theoretical and conceptual base, we center on the following questions:

Research Question 1: What factors might influence students' motivation and WTC during spoken interaction?

Research Question 2: What difficulties might students experience when being involved in spoken interaction?

Research Question 3: What kinds of instructional support (might) help boost student motivation and WTC during spoken interaction?

\section{Method}

This case-study was conducted in an EMI course within a Belgian university during the first semester of 2017-2018; this university has long been using English as a teaching medium for a range of postgraduate programs and exchange programs. A case study, because it is an in-depth study of a particular situation, is beneficial when studying complex settings to look for underlying explanations and to find implications for future practices. 


\section{Course Description}

This course was taught in English while introducing students to key concepts and skills in view of setting up educational research. English at Level B2, standardized by the Common European Framework of Reference for Languages, was required upon enrolment for the EMI program/courses taught in English at this university. Ten students (nine L2 students and one L1 student) enrolled in this course with various disciplinary backgrounds including educational science, psychology, counselling, and linguistics.

Four introductory lessons were organized as part of this course. These sessions were considered key to start off small group work that had to result in a group research report and an oral group presentation. The first lesson was focused on key concepts and methods of educational research; the second and third lessons were focused on modeling the student group assignment (the development of a review and a derived research model), and the final lesson was given as a feedback session to support students in completing the course assignment. The fact that final assessment would build on the quality of their group product (literature review, research model and oral presentation) was stated at the beginning of the first session. Student group composition was based on students' personal choice. In order to motivate students' involvement of spoken interaction, each group was encouraged to set up a study topic derived from members' shared interest, and poster paper was prepared for each group to present ongoing work for further spoken interaction with the lecturer and other groups in each lesson. As to the final oral presentation, students were expected to submit a video recording of presenting group research report.

\section{Research Participants}

Six students (five females and one male) out of 10 gave their informed consent to participate in interviews; one was a postgraduate student doing a degree at this university and five were exchange students from the Erasmus program. All students had the first language different from English, such as Croatian, Czech, Mandarin Chinese, Italian, and Spanish. In terms of the English proficiency level, one student was at $\mathrm{C} 1$ level, and the other five were at B2 level. Only one student had prior experiences in attending EMI based classes, the other students never experienced English as an L2 in an academic context before enrolling in this course. All participant input was coded in this study according to nationality and gender as shown in Table 1.

Table 1. Research Participants

\begin{tabular}{|c|c|c|}
\hline Participants & Nationality & Gender \\
\hline SpaF & Spanish & Female \\
\hline ItaF1 & Italian & Female \\
\hline ItaF2 & Italian & Female \\
\hline $\mathrm{CezF}$ & Czech & Female \\
\hline CroF & Croatian & Female \\
\hline TaiM & Taiwanese & Male \\
\hline
\end{tabular}

\section{Data Collection and Analysis}

One researcher, adopting the role of observer as participant, used multiple methods of data collection including: classroom observations with video-recording, and stimulated recall interviews with students. The other researcher, the course lecturer, contributed to giving feedbacks during data collection and analysis. The classroom observations with video-recording were conducted in each lesson to provide a holistic context for the researcher to take observations notes and reflect on the problems/issues related to students' motivation 
and WTC during spoken interaction. An interview guide for conducting semi-structured interviews with students was developed based on the video-recording content and observation notes. The interviews with individual students were conducted at the end of semester (December 11-14, 2017) to explore and reveal their self-reported perceptions of motivation, WTC and constructive instructional support during spoken interaction. The interviews were conducted in one researcher's office, and each interview was undertaken for about an hour. The interview guide includes three main sections: The first section is about students' motivation and WTC during spoken interaction; the second section is about the difficulties experienced by students during spoken interaction as filmed in the videos; the final section is about the instructional support which would help boosting student motivation and WTC during spoken interaction. During the interviews, when it came to the second section about the difficulties experienced by students during spoken interaction, the researcher also played back the video clips, edited for each student, and asked the student to recall and describe her/his thoughts at specific moments during that learning task (Chamot, 2005).

All the interviews were transcribed verbatim to develop a holistic and rich data set. The data were analyzed by following three steps: data reduction, data display, and verification; data reduction was made to produce a data set for each research question; data display was provided to compare and search the main themes emerging from the data, and verification was adopted to verify and conclude the research findings. Triangulation between different data sources (interviews with six L2 students) and different interpretation (discussion between researchers) was adopted during the analysis process to ensure the reliability and validity of research findings. The recordings made for classroom observations and interviews will be stored as digital files for 5 years and will be deleted afterwards to ensure confidentiality.

\section{Findings}

The findings presented below are drawn from the interviews conducted with six L2 students in relation to the three main themes of this research: motivation and WTC, difficulties, and instructional support; each will be discussed respectively.

\section{Motivation and WTC}

Whether or not students are motivated or willing to communicate by using L2 for spoken interaction is often associated with three factors, including students' self-efficacy, study topic, and learning environment.

\section{Students' self-efficacy}

Most students tended to refrain themselves from asking or answering questions autonomously during the lesson; the motivation to "speak up and interact" was inhibited by lack of self-efficacy in both language and knowledge. Hence, what they did was to passively answer a question when it was needed.

I am more shy than rest of us, and even more in English, because I don't feel secure of speaking... I am so afraid to say something bad, to pronounce bad, I think that people in my class speak better English than me... so they could laugh at me, I don't know[with laughing]. In all the classes in English, I tried to speak the least. (SpaF)

I am not actively speaking out in English with others, especially for this course, because I think I am not really used to using English to communicate with others or even express myself... if I want to speak out something in English, I need to translate my thought into English and then speak out, but it is not easy to me, so that will reduce my probability to speak out in English or even in this course... I mean somebody will judge whether or not I can speak something well or if I can speak English well, so that's why I seldom speak out something in English. (TaiM) 
It's because I don't usually make questions in the course... or I think that I might say something stupid, I usually don't say anything... yeah and also more secure maybe... I mean there was less chance to say something stupid. (CroF)

\section{Study topic}

The study content, whether or not students were interested in or had prior knowledge about, did affect students' motivation to some extent, especially in terms of their engagement in interaction with lecturer/peers.

I guess it's a starting point, because I mean, we chose a topic and we agreed on and we were willing to talk about it, maybe it become easier. Usually I interact more in the subject that I am interested in. For example, when I was in high school, I never interacted in math or physics...unless when it was necessary. (CroF)

I like the first lesson, it was nice, kind of critical thinking and we were discussing, I like this kind of lesson, but after it was just about the assignment. If you don't like the assignment, you don't like the lesson... and I think I didn't really understand assignment, so it was all mixed up... I think the topic was the best thing in this assignment, and I think it was because it was connected with me and with my experience, because I am doing this well. (CezF)

\section{Learning environment}

The learning environment, whether or not the lecturer or class members were friendly to talk to, also appeared being a factor in relation to student's motivation of speaking up and/or willingness to communicate.

I have to feel comfortable with the person, and it's more like internal problems... and also I am influenced by the surrounding, environment, if I don't feel comfortable with my colleagues. (CroF)

I think in the class, if the professor can immediately give us some feedbacks, especially for positive feedbacks, I think it will help us have more willingness to speak out with him, or even to express our opinions in the class. (TaiM)

I think they [groups members] speak much better English than me... but they are also like nice and friendly and close to me, so not being very secure about myself, but I can speak English. If I am not secure, I don't even talk. (SpaF)

However, some students were autonomously involved in asking and answering questions when there was a need to share and clarify what they had learned during the class.

I am kind of person when I have an idea, I want to share it, and I want to have feedback also from the professor, because I think that I have to take my chances here to learn more things possible. And so when I think of something, when I believe in something, I kind of feel the need to tell... but yeah here it's more difficult, because we are in another language... (ItaF1)

I felt like I have to answer, but not because he [lecturer] was looking at me or because he was expecting answers... or maybe I have some doubts about what the professor is saying, yeah, I want to gain more knowledge about the topic we are talking about. But it happens more when I am in the class... yeah I prefer to being more interactive, I know I don't have to waste time. (ItaF2) 
Chien \& Valcke, 2020

\section{Difficulties}

The main learning activities of this course built on students working as a pair/group and present their work progress during the feedback session in class; the students constantly needed to use L2 for spoken interaction with the lecturer and peers. The difficulties experienced by students during spoken interaction were found to be the use of academic language, understanding of disciplinary content, and attitudes toward learning activity.

\section{Use of academic language}

Most students were very self-conscious when using L2 to communicate with the lecturer or speak up in the class. The anxiety and/or lack of confidence in L2 was not only due to lack of phrases/words but also related to their personally-imposed requirement to speak good and formal academic language.

I am familiar with the topic, but in Spanish not in English, because I studied it in Spanish.. so although I know what I am talking about, I feel like in English it's not the same... it's like I know what I mean, but I don't know some terms, how to express...(SpaF)

It's mainly language... I think in my mind I also had the answer and I wanted to show this to the professor, but this answer was in Chinese. So when I wanted to tell this in English, I mean I wanted to translate into English, it's a little bit difficult to me. Because I needed to immediately respond something to him, but actually meanwhile I also needed to translate, right now, immediately, so it's really hard. (TaiM)

I think because I couldn't find the word fast... it's the way like that, if I had to just write it, it would be different, but if I have to speak in a quick way and answer it in a quick way, I have to think about it... I don't know it was because the fact that I was talking to a professor, and maybe also that I knew I had to choose the right and maybe more formal words, I don't know if it could be also for that reason, yeah, it's often because I can't find the right words. (ItaF1)

I am able to write in a formal way, but when I speak, I feel really informal. Speaking is not really a problem... reading sometimes when it's about scientific articles and there are words and expressions very uncommon. If I have to read and explain after reading, and that's difficult for me, when it's about those expressions. (ItaF2)

\section{Understanding of disciplinary content}

In general, the students felt not comfortable speaking up in public, especially when they didn't feel familiar with the context of learning. Hence, lack of contextual knowledge would lead to unwillingness in speaking up in the class, and further impede the learning and understanding of disciplinary content.

Sometimes, I have the feeling that he [the lecturer]didn't understand... that some theories or backgrounds that we didn't have, I think that sometimes he could have asked us what we knew or did not know... (ItaF1)

I feel like I have questions, I mean I don't understand anything... I stay confused instead of asking a question. But I think the assignment was very difficult for us, and that's why we are still confused... I didn't find like the moment to ask the questions, because I even didn't know what to question him [lecturer]. (SpaF)

It's just that I was kind of confused, then I didn't really know what to ask, and... confused about the requests, maybe, and there were very few lessons. I feel actually I am stupid for talking about things that I don't get, because it sounds like I would ask a stupid question, and I think it had to do with the 
fact that I never did statistics, and it was pretty difficult for me to get that mentally with the numbers and the scientific fact and everything. (CroF)

I think I didn't really talk that much. The first class [a different course] I did, but in this I didn't, because I think I didn't really understand what he wants from us, from me, I was confused. I have never heard about what the moderator, mediator and other variables before, so I was so polite but in a negative way. (CezF)

\section{Attitudes toward learning activity}

The learning activity such as oral presentation and writing assignment, if the goal or function was not well informed or communicated to students, would also create anxiety among students as well as a barrier for their involvement of learning and interaction between the peers.

I was a bit nervous at that time [first presentation], yeah it was more like a formal presentation, and was not just speaking, dialoguing and discussion. But yeah I felt it was more formal context... I wanted to express my ideas, but at the same time I was very critical about the way I explained them... when I have to do this kind of presentation, this kind of formal discussion, I want to have my time before, to prepare it and improve it, because otherwise I feel that I am not prepared enough. (ItaF1)

I didn't understand why, what's the purpose, there wasn't written [on syllabus], always something new. I didn't want to do anything that I don't understand why, I think that was the main problem that he [lecturer] didn't explain why we are doing this.... I mean I don't care about this assignment, I don't like it at all, so then I kind of giving up, almost everything what she [pair member] wanted, I agreed, not because it was just that good... I just wanted to finish... mainly what we have done was all her efforts. (CezF)

\section{Instructional Support}

The instructional support reflected and considered by students to be important and helpful in using L2 for spoken interaction included both social-emotional and cognitive supports provided by a lecturer. Some students also expected support could be given on language use.

\section{Social-emotional support}

The supportive and friendly attitudes shown by a lecturer would make students feel more comfortable and willing to communicate in a natural conversation.

They are different ways to correct somebody, maybe you can repeat the sentence they say before correctly, but not that you use it wrong... so that you could still speak with him [lecturer] without getting like more uncomfortable. (SpaF)

And maybe like some emotional support, he knows it's hard but we can do it, and everyone will get it, and then the purpose of why we are doing this, it's because of him or because of us, or what? Yeah, I miss that a lot. (CezF)

I think I take more advantages when the lesson is more interactive and sometimes there are breaks, and there are funny moments, and moment to relieve... it's less stressed. (ItaF2)

Giving "waiting time" and pause when asking or answering a question from/to students would help them feel more easy and less stressed to speak up. 
I know what to say, and I am like translating in my head and then I need to have the courage to talk... or thinking about how to say and not have any mistakes, because it's very difficult to me, and when I am going to talk, somebody else did...(SpaF)

Because the theoretical framework is not easy content to express or even to explain, you need to put more efforts to how I can translate it, so that's why I think I could not immediately reply to his question. But if the professor can give me more time, to let me express what I want to say, I think that will be perfect. (TaiM)

Maybe make pauses, because I usually don't raise hands, it is just like interrupting people, yeah maybe pauses will help me to... maybe interrupt what he said and add something that maybe he got from what I meant... sometimes, I don't use words in a right context, so I have to explain what I mean. (CroF)

The use of L1 for students who had lower self-efficacy in English would also help them engage in the group/peer discussion and feel more comfortable with the learning context.

I am not afraid of speaking English with you [researcher] or even with other peers... and maybe one factor to influence my speaking is because you are Taiwanese, so I think I can express something in the way that you will know, so I think it's really more comfortable to me. (TaiM)

But T [group member] is Italian and she knows Spanish... she speaks perfectly Spanish, so when sometimes we are, the three of us, and I am trying to explain something, I don't know how to say, I ask her how to say but in Spanish. I tried to speak English, but when I am like I don't know how to say, I speak with her [T] in Spanish. (SpaF)

\section{Cognitive support}

Having a prior understanding of students' knowledge and experience related to the disciplinary context and/or assignment work would diminish the risk of losing students' motivation and confidence in engaging in learning activities.

I think at the first step, it's more important to ask about the background, and the other one is just the consequence, I mean related to what your backgrounds are and asking you to do something and learn something more... because we are not the same levels, we come from different countries and everyone has followed different educational paths, and we don't come from the same faculty. (ItaF2)

Maybe if he [lecturer] could explain it better, more from the beginning... there was one day when he was speaking what was the work about, and the second day we were supposed to know what we had to do and start looking for pages and programs and maybe we needed more explanations to know what to do. (SpaF)

...reading the tables was kind of hard time for me... and it kind of came out of blue, because I know maybe psychology people did it, but I am in educational science and I have never done statistic course. (CroF)

I don't know exactly why [not feeling like to speak up], maybe it was connected with our assignments kind of, because I find it really difficult... and he [lecturer] didn't really ask us, if we have done this before or if we have some experience with this. I kind of feel that he just thought we are scientific workers and yeah... but it's not true. (CezF) 
Sometimes certain things for him [lecturer] were obvious, but they weren't for us... he explained clearly, but there were other things that maybe he thought we knew, but in fact, we hadless that background. I had never done academic research or articles, I was really interested in this, it would be useful for my thesis, but it has been sometimes a difficult learning process... because you learn by doing, and it's good, but if the professor can help also at the beginning, it's easier and quicker. (ItaF1)

Regarding the presentation, in which students were usually expected to perform speaking in a structured and systematic way, a clear guideline or preparation procedure could be given to students beforehand as well as assuring students not afraid of making mistakes. Following up the presentation, the lecturer could give some constructive feedbacks for students to reflect and review their work.

At that time [presentation shown in the video clip] I think I am not really sure about what's the content the professor wants... because at that time I think maybe I only need to do is that ... proposing the model and explaining the variables and that's all. But I don't know or....yeah maybe I need to give more definition or even the relationship between these variables. So that's why I am nervous at that time and even I don't know what I want to express, that's why...(TaiM)

I think it would be useful to know what we have to do...like we are clear that we have to choose an argument we like, and then we have to do these 3 points, and just develop the other stuff... previously because he[lecturer] always said "you choose you choose," so if I have to do choices for ever points, I am getting confused, and I don't know what to do. (CroF)

Maybe like "support me" before/during[presentation], and "appreciation" after [presentation] ...Before [presentation] just saying something like "don't worry if it's wrong... we will solve it or..." After he could have said something like "I really appreciate this, it was good"... of course he [lecturer] can say what we can improve, but at first he should say what was good. Because otherwise you feel like everything is wrong, I am not good enough and so on, and it's wrong. (CezF)

Before [the presentation] is to be clear about what the students have to do, like you have to give this this and this, and also give amount of time, like precise information, so that the students can organize and understand what they have to do. And during the presentation, well certainly you have to be interested in what the students are saying, the students have to feel that the professor wants to help them, and not to like waiting for your mistakes... like 2 days ago, we had presentation, and right after we finished, the professor gave us a feedback, like a quick feedback. I appreciate this, but I want more clarification than this, so you are not anxious about the evaluation and you can feel if you have done well, so yeah at the end of presentation, feedback and questions, maybe just to have a dialogue and discussion. (ItaF1)

Discussions within group would be less intimidated to students and give them more opportunities to speak up and communicate. More discussions within the pair/group, either between the peers or lecturer joining in the pair/group, could also help students to clarify and construct the knowledge as well as develop confidence in spoken interaction, especially speaking in public.

I think it would be good to have discussions with the professor alone, like not the professor to the class but the professor to the person or the group, like face to face, because I think you feel more comfortable to ask questions. (ItaF1) 
If I am with close friends... like with [group members], I think I always try to explain, it's difficult but I try. In the class no...(SpaF)

If I have to do some work, and I know I have to do a presentation in public, and I prepare it and I am sure about what I am saying, it's much more easier... if he [lecturer] comes and sees what we did, because if we go front, in front, it seems too much like a presentation, like sometimes you should have prepared for it, and it becomes awkward for you to be there. (CroF)

I like to talk with people, like discussion, and I don't like presentation. I mean just me speaking, I don't like it, I need interaction. (CezF)

If he [lecturer] can give us more opportunity to organize... like maybe we can do some good discussion and then he doesn't force everyone, need to speak out in front of the pubic... [also] if it's one by one situation, I think I can speak something well with him [lecturer], but if I need to speak out something in front of the pubic, it's not that comfortable. (TaiM)

\section{Language support}

Some students, particularly those who were not confident in their English proficiency, also expected support in relation to language use; the feedback given to the use of academic words and actual spoken interaction were considered by students to be important and helpful.

Actually it's (English) my third language. I don't think it's difficult to interact in English, because I always did it...but maybe we had some troubles of finding academic words to say, because we don't speak academic English... so that thing is the most difficult part, and for the other course also, because we have to write an academic paper, and we don't have the proper language to do it... I think that's difficult in any language, because you have to use the specific words which have specific meanings, so you can actually say what you mean, and I think that's difficult and challenging. (CroF)

[After the presentation] and then he also can give us some feedbacks regarding our English capacity. I mean maybe he can teach us about "how can you say is better.... what's the expression you can use is better"... yeah like the technical words. Maybe what's the appropriate, I mean the suitable vocabulary or what's the sentence you can use to express what you want to say. (TaiM)

He [lecturer] did once when he asked us the meaning of the word, and I answered, and he said "I know what you mean, but in English it's not the right word"... I think it's good when you have to use the precise words for subjects, yeah I think it would have a big impact, it makes you realize maybe you are not using the right words and there are more words to be used. (ItaF2)

\section{Discussion and Implications}

This study focused on exploring the self-reported perceptions of six L2 students during spoken interaction in an EMI course in regard to their motivation and WTC, difficulties, and instructional support. The main findings and implications are discussed below.

First, the results of this study showed that students' motivation and WTC for using L2 during spoken interaction seems related to their self-efficacy in English, study topic, and learning environment. Students' low self-efficacy, lack of knowledge or interest in study topic, and feelings of uneasiness with learning environment would often lead to an anxiety or lack of confidence in spoken interaction, and as a result, lack of motivation and WTC. Such findings implicate that attention need to be given for building up students' selfefficacy and/or confidence in language, while taking into account students' prior knowledge and experience 
related to the disciplinary content in an EMI context. Previous studies already showed the impact of enhancing English language learners' self-efficacy beliefs and other factors affecting learners' motivation such as the need for autonomy, competence and belonging (Chen et al., 2015; Haerens et al., 2015; Vansteenkiste et al., 2004), and their WTC such as choice of a topic, interlocutors' interaction, and interaction patterns (Rahman et al. 2010; Wong et al., 2005; Zarrinabadi, 2014). Such findings also support the complex and dynamic nature of the interplay between self-confidence, anxiety and perception of the learning environment as highlighted by Leger and Storch (2009).

Our findings also revealed that students using L2 during spoken interaction felt restricted because of difficulties in relation to academic language use, their understanding of the disciplinary content, and their attitudes toward the learning activity. Particularly, the lack of contextual knowledge in relation to the disciplinary content often led to unwillingness in speaking up in the class. Based on the cognitive load theory (Rousell et al., 2017), the learning of disciplinary content and a foreign language simultaneously is likely to be counterproductive; that is, the use of L2 can be a barrier for learning disciplinary content. In previous research, L2 students were also found having difficulties to understand the lecturers, participate in classroom interaction, and use English to communicate disciplinary content because of their lack of English proficiency (Airey, 2011; Hellekjær, 2010; Tsuneyoshi, 2005; Webb, 2002). However, our findings suggest that these difficulties are not mainly related to language proficiency, but also to students' confidence in using the language and level of contextual knowledge. Given that learning and language development occur through dialogue and interaction; these findings implicate that attention needs to be paid to students' language use support and to the scaffolding of learning as well as motivating students' interest in the learning activity. That is, lecturers could make efforts to create situational WTC in L2, as identified by Kang (2005), and this can be achieved by taking into account the interaction among excitement, responsibility, and security.

Finally, this study tried to explore the instructional support perceived by students to be useful when using L2 during spoken interaction in an academic context. We categorized the data into three aspects: socialemotional, cognitive, and language support. Previous research illustrated the practice of raising learners' selfefficacy as an essential approach to engage them into dialogue and learning (Mohd Khatib \& Maarof, 2015; Kim et al., 2015). Also, teaching strategies have been suggested, such as positive teacher feedback, choice of a topic, waiting time, short confirmatory phrases or smiling, etc. (Zarrinabadi, 2014). As can be derived from our findings, it seems essential to provide a social-emotional supportive environment, in which students feel comfortable to interact with lecturers and peers; more "waiting time" seems needed. Extra pauses given by the lecturer are appreciated by students as well as the use of L1 to communicate among peers. Cognitive support given by the lecturer, in terms of building more strongly on students' prior knowledge and experience about the disciplinary context seems important to elicit students' motivation and WTC when being involved in a learning task. When an oral task-such as a final presentation-is given to students, a structured guideline about conducting the task and a constructive feedback session, as well as giving time for a related group discussion could be helpful for students to prepare more fully for the task and to build up their confidence in speaking up and communicating their ideas. Lastly, when enrolling in an EMI course, it is important for L2 students to progress in their L2 language, to use the language more precisely during spoken interaction. A lecturer's support can be given by rephrasing the words/sentences used by students and/or by giving feedbacks about students' language use in general after completing a task.

\section{Limitations and Directions for Future Research}

The findings drawn from the present study were based on interviews with six L2 students with an English proficiency above an intermediate level. This might affect the generalization of our findings. Future research could pay attention to these variables. Though the question should be asked whether it is acceptable to give into the basic qualification criterion related to L2 learners' English proficiency. Future research could focus on 
looking for a critical baseline or benchmark in relation to a starting L2 language level. For example, in Taiwan, the English proficiency requirement for L2 students varies between different programs in higher education; future research developed in such setting could help identify other particular difficulties. Next, future research could also focus on exploring the efficacy of EMI instructional support, particularly to boost students' motivation and WTC during spoken interaction.

\section{References}

Airey, J. (2011). Talking about teaching in English: Swedish university lecturers' experiences of changing teaching language. Ibérica, 22, 35-54.

Bandura, A. (1997). Self-efficacy: The exercise of control. W. H. Freeman and Company.

Chamot, A. U. (2005). Language learning strategy instruction: Current issues and research. Annual Review of Applied Linguistics, 25, 112-130.

Chen, B., Vansteenkiste, M., Beyers, W., Boone, L., Deci, E. L., Van der Kaap-Deeder, J., Duriez, B., Lens, W., Matos, L., Mouratidis, A., Ryan, R. M., Sheldon, K. M., Soenens, B., Van Petegem, S., \& Verstuyf, J. (2015). Basic psychological need satisfaction, need frustration, and need strength across four cultures. Motivation and Emotion, 39(2), 216-236.https://doi.org/10.1007/s11031-014-9450-1

Dörnyei, Z. (2003). Attitudes, orientations, and motivations in language learning: Advances in theory research, and application. Language Learning, 53, 3-32. https://doi.org/10.1111/1467-9922.53222

Dörnyei, Z. (2005). The psychology of the language learner, individual differences in second language acquisition. Lawrence Erlbaum Associates.

Ersanli, C. Y. (2015). The relationship between students' academic self-efficacy and language learning motivation: A study of 8th graders. Social and Behavioral Sciences, 199, 472-478.

Ferris, D., \& Tagg, T. (1996). Academic oral communication needs of EAP learners: What subject matter instructors actually require. TESOL Quarterly, 3O(1), 31-58.

Gardner, R. C. (1985). Social psychology and language learning: The role of attitudes and motivation. Edward Arnold.

Gist, M. E., \& Mitchell, T. R. (1992). Self-efficacy: A theoretical analysis of its determinants and malleability. Academy of Management Review, 17(2), 183-211.

Haerens, L., Aelterman, N., Vansteenkiste, M., Soenens, B., \& Van Petegem, S. (2015). Do perceived autonomy-supportive and controlling teaching relate to physical education students' motivational experiences through unique pathways? Distinguishing between the bright and dark side of motivation. Psychology of Sport and Exercise, 16, 26-36.

Hellekjær, G. O. (2010). Lecture comprehension in English-medium higher education. Hermes, 45, 11-34.

Hellsten, M., \& Prescott, A. (2004). Learning at university: The international students experience. International Education Journal, 5, 344-351.

$\mathrm{Hu}, \mathrm{G}$. (2007). The juggernaut of Chinese-English bilingual education. In A. W. Feng (Ed.), Bilingual education in China: Practices, Policies and Concepts (pp. 94-126). Multilingual Matters.

Jackson, J. (2002). Reticence in second language case discussions: Anxiety and aspirations. System, 3o(1), $65-84$.

Kang, S. J. (2005). Dynamic emergence of situational willingness to communicate in a second language. System, 33, 277-292. 
Kim, D. H., Wang, C., Ahn, H. S., \& Bong, M. (2015). English language learners' self-efficacy profiles and relationship with self-regulated learning strategies. Learning and Individual Differences, 38, 136142.

Komarraju, M., \& Nadler, D. (2013). Self-efficacy and academic achievement: Why do implicit beliefs, goals, and effort regulation matter? Learning and Individual Difference, 25, 67-72.

Leger, D. S., \& Storch, N. (2009). Learners' perceptions and attitudes: Implications for willingness to communicate in an L2 classroom. System, 37, 269-285.

McCroskey, J. C., \& Baer, J. E. (1985), Willingness to communicate: The construct and its measurement. Paper presented at the annual convention of the Speech Communication Association, Denver, CO.

McCroskey, J. D., \& Richmond, V. P. (1991). Willingness to communicate: A cognitive view. In M. BoothButterfield (Ed.), Communication, cognition, and anxiety (pp. 19-37). Sage.

Maclintyre, P. D., Clement, R., Dörnyei, Z., \& Noels, K. A. (1998). Conceptualizing willingness to communicate in a L2: A situational model of L2 confidence and affiliation. The Modern Language Journal, 82, $545-562$.

Mehrgan, K. (2013). Willingness to communicate in second language acquisition: A case study from a socioaffective perspective. Journal of Comparative Literature and Culture, 2(4), 172-175.

Mohd Khatib, F. M., \& Maarof, N. (2015). Self-efficacy perception of oral communication ability among English as a second language (ESL) technical students. Social and Behavioral Sciences, 204, 98-104.

Pajares, F., \& Johnson, M. J. (1996). Self-efficacy beliefs and the writing performance of entering high school students. Psychology in the Schools, 33(2), 163-175.

Pecorari, D., Shaw, P., Irvine, A., \& Malmstöm, H. (2011). English for academic purposes at Swedish universities: Teachers' objectives and practices. Ibérica, 22, 55-78.

Piller, I., \& Cho, J. (2013). Neoliberalism as language policy. Language in Society, 42, 23-44.

Rahman, S., Mazlan, M., Kummin, S., Yasin, R. M., \& Meerah, T. S. M. (2010). Examining the role of language on students achievement: A study on the use of second language as a medium of instruction in teaching science subject in Malaysia. Social and Behavioral Sciences, 9, 1261-1265.

Rousell, S., Joulia, D., Tricot, A., \& Sweller, H. (2017). Learning subject content through a foreign language should not ignore human cognitive architecture: A cognitive load theory approach. Learning and Instruction, 52, 69-79.

Ryan, R. M., \& Deci, E. L. (2000). Intrinsic and extrinsic motivations: Classic definition and new directions. Contemporary Educational Psychology, 25, 54-67. https://doi.org/10.1006/ceps.1999.1020

Shih, S., \& Alexander, J. M. (2000). Interacting effects of goal setting and self- or other-referenced feedback on children's development of self-efficacy and cognitive skill within the Taiwanese classroom. Journal of Educational Psychology, 92, 536-543.

Tatzl, D. (2011). English-medium masters' programmes at an Austrian university of applied science: Attitudes, experiences and challenges. Journal of English for Academic Purposes, 10, 252-270.

Tsuneyoshi, R. (2005). Internationalization strategies in Japan: The dilemmas and possibilities of study abroad programs using English. Journal of Research in International Education, 4, 65-86.

Vansteenkiste, M., Simons, J., Lens, W., Sheldon, K. M., \& Deci, E. L. (2004). Motivating learning, performance, and persistence: The synergistic effects of intrinsic goal contents and autonomysupportive contexts. Journal of Personality and Social Psychology, 87(2), 246-260. https://doi.org/10.1037/0022-3514.87.2.246 
Vasile, C., Marhan, A. M., Singer, F. M., \& Stoicescu, D. (2011). Academic self-efficacy and cognitive load in students. Social and Behavioral Science, 12, 478-482.

Wang, C., Schwab G., Fenn, P., \& Chang M. (2013). Self-efficacy and self-regulated learning strategies for English language learners: Comparison between Chinese and German college students. Journal of Educational and Developmental Psychology, 3(1). 173-191.

Webb, V. (2002). English as a second language in South Africa's tertiary institutions: A case study at the University of Pretoria. World Englishes, 21, 49-61.

Wilkinson, R. (2013). English-medium instruction at a Dutch university: Challenges and pitfalls. In A. Doiz, D. Lasagabaster, \& J. M. Sierra (Eds.), English-medium instruction at universities: Global challenges (pp. 3-24). Multilingual Matters.

Wong, S. L. (2005). Language learning strategies and language self-efficacy: Investigating the relationship in Malaysia. RELC Journal, 36(3), 245-269.

Woolfork, A. (2008). Educational psychology (10th ed.). Allyn and Bacon.

Zarrinabadi, N. (2014). Communicating in a second language: Investigating the effect of teacher on learners' willingness to communicate. System, 42, 288-295.

Zimmerman, B. J., \& Kitsantas, A. (2005). Homework practices and academic achievement: The mediating role of self-efficacy and perceived responsibility belief. Contemporary Educational Psychology, 3o, $397-417$.

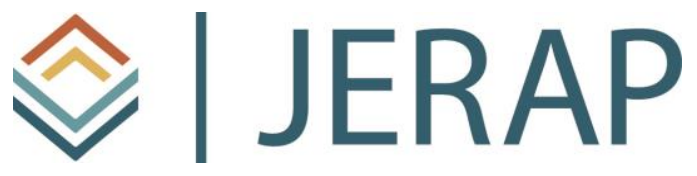

The Journal of Educational Research and Practice is a peerreviewed journal that provides a forum for studies and dialogue about developments and change in the field of education and learning. The journal includes research and related content that examine current relevant educational issues and processes. The aim is to provide readers with knowledge and with strategies to use that knowledge in educational or learning environments. JERAP focuses on education at all levels and in any setting, and includes peer-reviewed research reports, commentaries, book reviews, interviews of prominent individuals, and reports about educational practice. The journal is sponsored by the Richard W. Riley College of Education and Leadership at Walden University, and publication in JERAP is always free to authors and readers. 